\title{
PRODUÇÃO E COMERCIALIZAÇÃO DE ALIMENTOS FRENTE A LEGISLAÇÃO VIGENTE: O CASO DO MERCADO POPULAR DE SÃO GABRIEL DA PALHA - ES.
}

\author{
Recebido em 30/11/2020, aprovado em 13/03/2020 \\ 10.30612/mvt.v6i11.10764 \\ Cristina Matielo ${ }^{17}$ \\ Claudinei Lucio Santos ${ }^{18}$
}

\begin{abstract}
No Brasil, a produção de alimentos para o mercado interno, apesar de ser considerada pelos valores dominantes como o resultado de uma agricultura subalterna, torna-se cada vez mais uma opção estratégica para se alcançar a soberania alimentar do país. (CALDART, 2012, p. 32)
\end{abstract}

\begin{abstract}
RESUMO: Este trabalho tem como objetivo apresentar a experiência de produção e comercialização das famílias camponesas vinculadas ao Mercado Popular de Alimentos de Sáo Gabriel da Palha, Espírito Santo, e os desafios enfrentados por estas diante das exigências jurídicas frente a legislação sanitária em vigor. Considerando que a produçâo livre de agrotóxicos se tornam cada vez mais um clamor e essencial para a vida humana, esse trabalho possibilitará, recolocar o debate sobre as formas de organizaçáo da produção e, por sua vez, os processos de comercializaçáo dos alimentos, que no caso do Mercado Popular encontra obstáculos legislativos no que tange a forma camponesa de produzir, por conta da lógica capitalista de produzir hegemonizada pelo agronegócio, que impôs sobre as demais formas, um processo de padronizaçáo e homogeneização dos alimentos, produzindo um padrão alimentar imposto pelas grandes empresas, onde não se leva em consideração a saúde humana, o bem-estar social e a função social da produção em detrimento do lucro. Através desse processo, a produção camponesa é cada vez mais criminalizada e excluída dos mercados locais. A metodologia utilizada nesta pesquisa, está baseado na revisão bibliográfica, entrevistas com famílias vinculadas ao Mercado Popular de Alimentos em São Gabriel da Palha - ES, e entrevistas com os consumidores dos alimentos vendidos neste Mercado. O resultado obtido, nos evidenciou que a regra imposta pela legislação não dialoga com o cenário atual, que é de escassez de alimentos, tão pouco com as condiçóes de produçáo das famílias, não se valorizando as identidades, as formas de cultura e os saberes populares acumulados no espaço-tempo.
\end{abstract}

Palavras-chave: Legislação. Mercado. Produção. Comercialização.

17 Militante do Movimento dos Pequenos Agricultores do Espírito Santo, advogada popular formada pela Universidade Estadual de Feira de Santana (UEFS) - BA. crismpaes@gmail.com

18 Militante do MST- RO e Via Campesina, Bacharel em Direito pela Universidade Estadual de Feira de Santana (UEFS) - BA, e membro do Instituto Territórios e Justiça INTERJUS. claudineisantos@mst.org.br 
FOOD PRODUCTION AND MARKETING AGAINST CURRENT LEGISLATION:

THE CASE OF THE POPULAR FOOD

MARKET OF SÃO GABRIEL DA PALHA - ES

\begin{abstract}
This paper aims to present the experience of production and marketing of peasant families linked to the Popular Food Market of São Gabriel da Palha, Espírito Santo, and the challenges they face in the face of legal requirements under current health legislation. Considering that pesticide-free production is increasingly becoming an outcry and essential for human life, this work will enable the debate on the forms of production organization and, in turn, the processes of commercialization of food to be restored, that in the case of the Popular Market, there are legislative obstacles regarding the peasant way of producing, due to the capitalist logic of producing hegemonized by agribusiness, which imposed on the other forms a process of standardization and homogenization of food, producing an imposed food standard, by large companies, where human health, social welfare and the social function of production are not taken into account, to the detriment of profit. Through this process, peasant production is increasingly criminalized and excluded from local markets. The method used in this research is based on literature review, interviews with families linked to the market, and interviews with consumers of foods sold in the market. The result showed that the rule imposed by the legislation does not dialogue with the current scenario, which is food shortage, nor with the production conditions of families, not valuing identities, forms of culture and popular knowledge. accumulated in space time.
\end{abstract}

Keywords: legislation. Market. Production. Commercialization.

\title{
PRODUCCIÓN Y COMERCIALIZACIÓN DE ALIMENTOS FRENTE A LEGISLACIÓN VIVENTE: EL CASO DEL MERCADO POPULAR DE SÃO GABRIEL DA PALA - ES
}

RESUMEN: Este trabajo tiene como objetivo presentar la experiencia de producción y comercialización de las familias campesinas vinculadas al Mercado Popular de Alimentos de São Gabriel da Palha, Espírito Santo, y los desafíos que enfrentan en vista de los requisitos legales en virtud de la legislación sanitaria vigente. Teniendo en cuenta que la producción libre de agrotóxicos se está convirtiendo cada vez más en un deseo y esencial para la vida humana, este trabajo permitirá reemplazar el debate sobre las formas de organización de la producción y, a su vez, los procesos de comercialización de alimentos, que en el caso de Mercado Popular se encuentra con obstáculos legislativos con respecto a la forma campesina de producir, debido a la lógica capitalista de producir hegemonizada por el agronegócio, que impuso a las otras formas, un proceso de estandarización y homogeneización de alimentos, produciendo un estándar alimentario impuesto por grandes empresas donde no se tiene en cuenta la salud humana, el bienestar social y la función social de 
la producción en detrimento de las ganancias. A través de este proceso, la producción campesina está cada vez más criminalizada y excluida de los mercados locales. El método utilizado en esta investigación se basa en la revisión de la literatura, entrevistas con familias vinculadas al mercado y entrevistas con consumidores de alimentos vendidos en el mercado. El resultado mostró que la norma impuesta por la legislación no dialoga con el escenario actual, que es la escasez de alimentos, ni con las condiciones de producción de las familias, no valora las identidades, las formas de cultura y el conocimiento popular acumulado en el espacio tiempo.

Palavras Clave: legislación. Mercado. Producción. Comercialización.

\section{INTRODUÇÃO}

É verdade que depois de derrubadas as cercas do latifúndio, outras se levantarão, as cercas do Judiciário, as cercas da polícia (ou das milícias privadas), as cercas dos meios de comunicação de massa. [...] Mas, é verdade também, que cada vez mais caem cercas e a sociedade é obrigada a olhar e a discutir o tamanho das desigualdades, o tamanho da opulência e da miséria, o tamanho da fartura e da fome. (Pedro Tierra)

A crise econômica mundial fruto da lógica de funcionamento do capitalismo, que se hospeda nas mais diversas economias desse de 2008, ampliou de forma significativa, o interesse do capital financeiro pelo mercado de terras agrícolas no Brasil (SAUER; LEITE, 2012). De acordo com o Banco Mundial entre 2008 e 2009 foram "[...] celebrados acordos envolvendo a compra ou arrendamento de 56,6 milhóes de hectares no mundo" (KÜNZLI, 2015, p.8) principalmente no continente africano, asiático e latino-americano. Tal investida está diretamente relacionada com o aumento do preço dos gêneros alimentícios (ZIEGLER, 2013), com a demanda do mercado global por biocombustíveis e com o descobrimento de novas reservas de petróleo e carvão. A lógica aqui, é transformar a terra em ativos financeiros, alterando a função das terras agricultáveis que outrora era "lócus" de reprodução social, passando agora a ter um "valor como se fosse uma ação negociável de uma empresa [...] fazendo com que as terras [...] sofram ação dos especuladores para que os ativos se valorizem" (CAMPELO, 2017).

Entretanto, esse processo prescindido de um "pacto de poder" (DELGADO, 2013) hegemonizada pelo o que se convencionou a chamar de agronegócio, cujos interesses residem na ampliaçáo e apropriação da renda da terra em detrimento das comunidades locais que exploram a terra segundo uma lógica que difere do mercado especulativo, produzindo e alimentando os conflitos agrários, a escassez de alimentos e alta nos preços dos alimentos.

$\mathrm{Na}$ contramão desse processo, vem ocorrendo nos últimos períodos, um aumento crescente no número de famílias camponesas que passa por uma espécie de retorno às "raízes", ou seja, voltando a produzir alimentos saudáveis, de forma diversificada, com dois objetivos finais: primeiro para seu auto sustento, e segundo para complementar a renda familiar. Desta produção, uma parte significativa passa processos de processamento. Damos como exemplo, o panifício, a agroindústria do leite, os doces, e até processamento mais complexos, como é o caso de abates de pequenos animais. 
Tais produtos são comercializados em escalas pequenas nos mercados locais, como feiras livres, Mercado Popular de Alimentos e em programas de compras governamentais, como foi o caso Programa de Aquisição Alimentos (PAA) e o Programa Nacional de Alimentação Escolar (PNAE).

Todavia, estes processos de comercialização, não ocorrem de forma pacífica, estas famílias passam pelo o que podemos chamar de criminalizaçáo institucional na forma de produzir e comercializar. E este processo de criminalização, encontra amparo dentro dos marcos regulatórios, que foram e são construídos alinhados a lógica da produção de grande escala, voltada para a busca do lucro. Esta lógica impóe para a pequena agricultura o mesmo enquadramento jurídico normativo.

Assim, este trabalho tem como objetivo no primeiro momento narrar as formas de produção e comercialização das famílias camponesas vinculadas ao mercado Popular de São Gabriel da Palha, frente às exigências normativas sanitárias vigentes, tendo como fio condutor, o direito legislado. Em um segundo momento, abordaremos os processos de produção agroindustrial e produção camponesa. E no terceiro, analisar a legislação brasileira sobre controle sanitário sobre estas duas formas de produção.

Como metodologia utilizamos para este trabalho a pesquisa bibliográfica, entrevistas tanto com famílias envolvidas no processo de produção e comercialização, como no consumo, e pesquisa documental a partir de registros do Movimento dos Pequenos Agricultores (MPA).

Como forma de contribuir para uma melhor leitura e entendimento, este trabalho está estruturado da seguinte forma:

No primeiro capítulo, intitulado de: MODELOS DE PRODUÇÃO NO CAMPO BRASILEIRO, abordaremos as diferenças fundamentais entre a formas de produção e no uso da terra, tendo como base o que denominamos de sistema camponês e sistema capitalista baseado no agronegócio.

No segundo capítulo, intitulado de: LEGISLAÇÃO SANITÁRIA FRENTE AOS MODELOS DE PRODUÇÃO DE ALIMENTOS, trataremos da legislação e do controle sanitário, e da legislação e vigilância sanitária frente a estes modelos de produção. Destacando os impasses que este conjunto de normas jurídicas, impóem as famílias camponesas.

No terceiro e último, intitulado de: O CASO DO MERCADO POPULAR DE ALIMENTOS DE SÃO GABRIEL DA PALHA, apresentaremos o que é o mercado popular de alimentos, seu histórico, sua relação com a cidade, sua estrutura organizativa e os atuais limites e desafios que estão colocados para as famílias envolvidas no processo de produção e comercialização.

E por fim, e sem a pretensão de esgotar o debate que é vasto e complexo, apresentamos nossas consideraçóes finais, no intuito de buscando apontar algumas ponderaçóes que merecem destaque diante da reflexáo aqui apresentada, tendo como objetivo estimular e contribuir com o debate no âmbito da academia, ao mesmo tempo, chamar a atenção dos legisladores, para as mudanças necessárias acerca da produção e comercialização de alimentos limpos produzidos no Brasil, e dos desafios que estão colocados para o mercado popular de alimentos de São Gabriel, conforme extraído das nossas observaçóes.

\section{MODELOS DE PRODUÇÃO NO CAMPO E A QUESTÃO ALIMENTAR}

Os alimentos foram elementos centrais para o desenvolvimento da humanidade. Foi com ele e com seus excedentes que se organizaram mecanismos de processamentos mais complexos. Muitos conflitos decorreram da disputa pelo alimento e pelas condiçóes de sua produção, estas disputas, se 
deram principalmente pelo o acesso a água, terra, e de mais meios de produção. A falta de alimento adequado acarreta profundas crises na sociedade, pois a existência da vida humana depende os alimentos. Portanto, conforme defende o Movimento dos Pequenos Agricultores (MPA), a produção, distribuição e consumo de alimentos são produçôes sociais e, como tal, podem (e devem) ser alteradas diante da crise alimentar na qual nos encontramos.

Com o avançar do capitalismo, os alimentos, se transformou em mercadoria concentrada nas mãos de algumas grandes empresas.

$\mathrm{O}$ atual sistema alimentar globalizado transformou o alimento em mercadoria, concentrando o modelo de produção, distribuição e consumo em algumas transnacionais (do agronegócio, das redes varejistas, dos supermercados). O preço dos alimentos é determinado nas bolsas de valores - como a bolsa de Chicago. Neste modelo, se você não pode comprar, você não conta. O fundamental é vender. Mas isso nem sempre foi assim, e no futuro não poderá ser desta forma. (ESTEVE, 2017, p. 16).

Contudo, acreditamos que os alimentos não devem ser concebidos como mercadoria, e sim direito humano, pois sua produção, distribuição e consumo implica nas condições da existência humana e consequentemente na soberania alimentar.

Ao analisemos a política brasileira no que se refere ao estoque público de alimentos, constata-se que esta política foi desregulada, concentrada e desmontada, depois da criação da Companhia Nacional de Abastecimento (CONAB) fruto da fusão de três outras empresas públicas: Companhia Brasileira de Alimentos (COBAL), Companhia de Financiamento da Produção (CFP) e a Companhia Brasileira de Armazenamento (CIBRAZEM), deixando o país em condição de vulnerabilidade em caso catástrofe natural ou guerra.

Além disto, ouve uma diminuição na quantidade de alimentos utilizados pela humanidade em sua dieta alimentar. Matielo (2018), faz a seguinte constatação:

Os povos da pré-história alimentavam-se com mais de 1.500 (mil e quinhentas) espécies de plantas. Há 150 (cento e cinquenta) anos, a humanidade alimentavase com produtos de 3.000 (três mil) espécies vegetais, sendo 90\% (noventa por cento) delas produzidas e consumidas em seus países de origem, portanto nota-se a enorme mudança nos últimos anos. Entre 1970 e 2008, houve uma redução em 30\% (trinta por cento) da biodiversidade no mundo: desde então, passamos a consumir $50 \%$ (cinquenta por cento) mais recursos naturais que nossa capacidade de produção. Vale ressaltar que isto ocorre no mesmo período da implementação da revolução verde (uso intensivo dos agroquímicos na agricultura). Em 2003 , apenas 15 (quinze) espécies respondiam por 90\% (noventa por cento) dos alimentos vegetais, e apenas quatro cultivos - milho, soja, trigo e arroz - respondiam por 70\% (setenta por cento) do consumo. Atualmente, sáo 58 (cinquenta e oito) empresas que controlam a produção de alimentos no mundo. (MATIELO, 2018, p. 22) 
Houve também a concentração sobre o domínio das sementes agricultável na agricultura, onde [...] seis empresas controlam $60 \%$ (sessenta por cento) das sementes utilizadas na agricultura, números muito preocupantes se compararmos com 1980, onde as empresas chegavam a dominar 1\% (um por cento) do mercado mundial. (ESTEVE, 2013, p. 16).

Em um primeiro momento no caso do Brasil, este processo tem relação com o surgimento do agronegócio na agricultura baseado na monocultura, juntamente com o pacote tecnológico, que no caso das sementes se convencionou a chamar de "Terminator" (que são as sementes estéreas) e a concentraçáo da terra, que juntos produziu um processo de homogeneização das cadeias produtivas.

Em um segundo momento, este sendo o mais recente, Santos (2018) em trabalho monográfico, diz que faz parte da crise do financeiro de 2008, e da crise dos alimentos de 2010 que provocou um deslocamento de capitais externos (estrangeiro) sobre os bens da natureza e, em especial, sobre a terra. Essa corrida mundial por terra e pelos bens da natureza, faz parte de um contexto global recente, que está associado às demandas pelos chamados "4Fs": food (alimentos), fiber (fibras/ração), forest (floresta) e fuel (combustível ou energia) (SANTOS 2018, p. 60) \& (BANCO MUNDIAL, 2010).

Santos ainda observa que:

[...] na geopolítica da questão agrária, que o processo da estrangeirizaçâo da terra, se apresenta um processo de Estado-nação, em que as empresas de países ricos e até os próprios países, compram e arrendam terras nos países mais "pobres" para produzir agroenergia e commodities agrícolas, apresentando assim as seguintes consequências: (a) aumento no preço da terra; (b) ameaça aos territórios camponeses e indígenas; (c) acirramento dos conflitos agrários; (d) reforço do neocolonialismo e aumento da dependência e ameaça à soberania nacional; (e) ameaça da soberania alimentar, que se traduz em ameaça à soberania dos povos. [...] (SANTOS, 2018, p. 66)

No caso do Brasil, grosso modo se conflita dois grandes modelos de produção. O modelo baseado no agronegócio, e o modelo baseado na agricultura camponesa.

Para melhor entendermos estes dois modelos de agricultura do ponto de vista conceitual e político, vamos nos apoiar nas contribuiçóes de Horacio Martins de Carvalho 2012, Francisco de Assis Costa, 2012, Sergio Pereira Leite, 2012, Leonilde Servolo de Medeiros, 2012 e Cristina Matielo, 2018.

Segundo Carvalho e Costa o conceito de agricultura camponesa, pode ser definido da seguinte forma:

Agricultura camponesa é o modo de fazer agricultura e de viver das famílias que, tendo acesso à terra e aos recursos naturais que ela suporta, resolvem seus problemas reprodutivos por meio da produção rural, desenvolvida de tal maneira que não se diferencia o universo dos que decidem sobre a alocação do trabalho dos que se apropriam do resultado dessa alocação (apud CALDART 2012, p. 28).

Em recente trabalho monográfico, Matielo traz a seguinte contribuição, em relação ao conceito de a agricultura camponesa: $\mathrm{O}$ camponês possui um vínculo afetivo e interativo com o meio em que vive e reproduz sua forma e modo de vida, estabelecendo relaçóes sociais e materiais de modo a desenvolver sua cultura. (MATIELO, 2018, p. 27). 
Em relação ao agronegócio, Leite e Medeiros nos traz a seguinte definição:

O termo agronegócio, de uso relativamente recente em nosso país, guarda correspondência com a noção de agribusiness, cunhada pelos professores norte- americanos John Davis e Ray Goldberg nos anos 1950, no âmbito da área de administração e marketing. $\mathrm{O}$ termo foi criado para expressar as relaçóes econômicas (mercantis, financeiras e tecnológicas) entre o setor agropecuário e aqueles situados na esfera industrial (tanto de produtos destinados à agricultura quanto de processamento daqueles com origem no setor), comercial e de serviços. (apud CALDART, 2012, p. 81)

Podemos extrair desses conceitos duas grandes chaves de definiçôes. A primeira é que agricultura é uma atividade eminentemente humana (PLOEG 2008) e, por isso, pode ser realizada de diferentes formas. No cenário brasileiro atual, temos uma representada pelo agronegócio e outra pelo campesinato com finalidades também diferentes.

O gráfico abaixo nos ajuda a intender como estes dois modelos se localizam dentro da política econômica atual, e qual função social cada um tem na sociedade brasileira.

Figura 1 - Gráfico comparativo modelo camponês e modelo capitalista representado pelo Agronegócio.

\section{Os Camponeses}

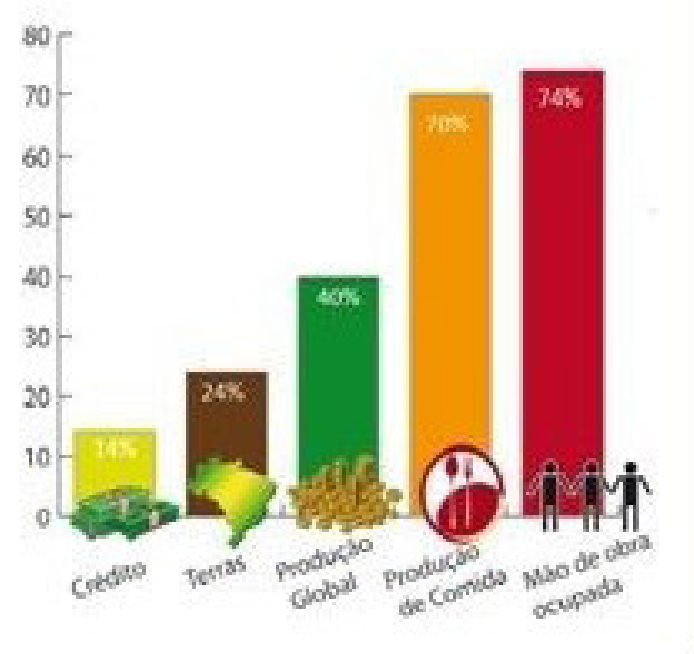

OAgronegócio

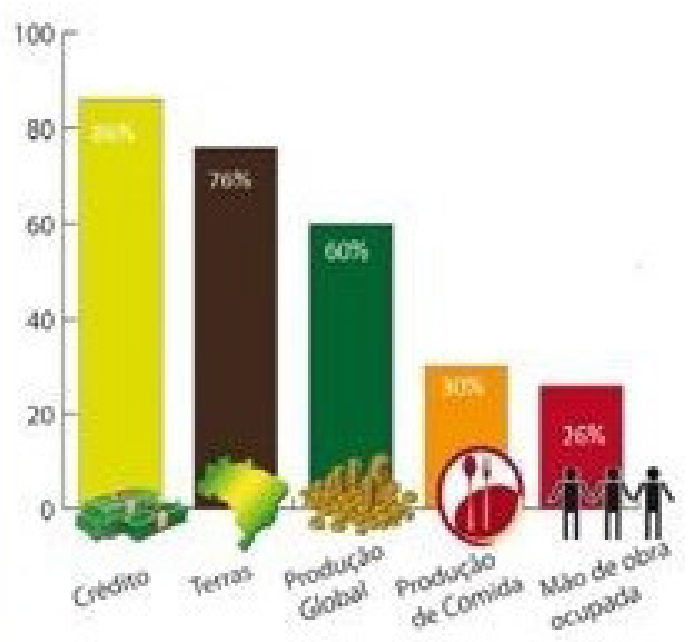

Fonte: Censo Agropecuário 2006.

O gráfico demonstra que, com apenas 14\% (catorze por cento) dos créditos e 24\% (vinte e quatro por cento) das terras, o campesinato responde por $40 \%$ (quarenta por cento) do PIB agrícola, com $70 \%$ (setenta por cento) da produçáo de alimentos que abastece a populaçáo brasileira e ainda gera 74\% (setenta e quatro por cento) dos empregos no campo. Por outro lado, o Agronegócio consegue acessar $86 \%$ (oitenta e seis por cento) dos créditos, $76 \%$ (setenta e seis por cento) das terras e responde por apenas $60 \%$ (sessenta por cento) do PIB agrícola, produzindo apenas 40\% (quarenta por cento) do alimento que vai para mesa do povo e gerando somente $26 \%$ (vinte e seis por cento) dos empregos no campo. 
É importante frisar, que estes modelos são antagônicos pois, enquanto o agronegócio modelo voltado para o mercado externo e se baseia no monocultivo, no uso extensivo de agrotóxicos e na grande propriedade, a agricultura camponesa, que é voltado para o mercado interno, implica em uma ampla distribuição da terra e produção diversificada e limpa.

Portanto, podemos concluir que se trata de modelos completamente distintos, onde não é possível encontrarmos pontos de consenso sobre o uso social da terra, estando os mesmos dentro de concepçôes econômicas antagônicas. Estes modelos se encontram em permanente disputa no campo e na sociedade. Disputam a lógica de uso da terra e do território, e disputam a concepção ideológica de agricultura na sociedade, baseado nos modelos aqui apresentados.

\section{A LEGISLAÇÃO SANITÁRIO FRENTE AOS MODELOS DE PRODUÇÃO DE ALIMENTOS}

A humanidade passou a ter conhecimento da composição dos alimentos, suas propriedades e seus valores nutricionais, com o avanço e aprimoramento da ciência. A partir disso foi possível proporcionar uma maior oferta de produtos alimentícios, vindo a substituir a forma simples de subsistência que a humanidade tinha, perdendo-se a estreita harmonia entre a natureza, seres humanos, conhecimentos das plantas próprias para o consumo.

Entretanto, se por um lado o desenvolvimento trouxe benefícios no campo do aumento da produção, melhoria na conservação, maior diversificação, e "atendimento" das necessidades nutricionais, por outro lado também cresceram os riscos e as problemáticas decorrentes dessa modernização, com o contaminação dos alimentos, a perda de garantia da qualidade do alimento, a desconsideração do valor de uso dos produtos, sujeitos aos preços impostos por um mercado que desconsidera a vida humana, a perda da consciência dos produtores sobre o papel e importância de seu trabalho.

Nesta toada, o debate sobre a segurança alimentar passa a ser uma questão necessária para se garantir uma qualidade saudável dos alimentos e assegurar a saúde da população. Por tanto, demandasse medidas e esforços do próprio Estado, a fim de minimizar e evitar doenças causadas por alimentos contaminados e impróprios para o consumo. Segundos dados da Organização Mundial da Saúde (OMS), em seu relatório intitulado "Fact Sheet no 237, January 2002", em países industrializados, anualmente, mais de 30\% (trinta por cento) das doenças são de origem alimentar (ALMEIDA-MURADIAN, 2011, p.2). Cabe por tanto ao poder público, criar mecanismos que garantam a oferta de alimentos seguros à população.

Neste sentido, é compreensível a importância da existência de legislações que estabeleçam critérios de qualidade que compreendam todas as etapas de produção, processamento, armazenamento, conservação até se chegar à venda.

É necessário ainda reconhecer, que nem sempre a legislação que deveria garantir a qualidade dos alimentos cumpre o seu papel: o que se evidencia muitas vezes é uma legislação que atende aos lobbies de grandes empresas e indústrias, ao mesmo tempo em que se impõe medidas rigorosas às pequenas agroindústrias familiares. Muitas vezes, o controle sanitário acaba por avalizar um alimento totalmente maléfico à saúde como algo que náo causa riscos e danos a ela. Há exemplo disto em vários produtos, que em tese, são regularizados, inspecionados pelos devidos órgáos de controle sanitário, e legalmente autorizados para o consumo humano, facilmente encontrados nos supermercados, porém repletos de contaminaçóes por agrotóxicos, conservantes, muitos transgênicos e tantos outros que, devido ao seu processo de beneficiamento, são mais "imitaçóes" de alimentos do que alimentos propriamente ditos. 


\section{LEGISLAÇÃO E CONTROLE SANITÁRIO}

No Brasil, a organização administrativa voltada para o controle de alimentos é bastante complexa. Há vários órgáos atuando sobre este assunto, inclusive estados e municípios que legislam suplementarmente, conforme determina a Constituição Federal de 1988 (ALMEIDA-MURADIAN, 2011, p.2).

Podemos facilmente perceber que o marco legal da produção de alimentos é definido e regulado por uma série de leis, normas e decretos que passam a compor o sistema sanitário brasileiro.

As normas sanitárias estabelecem os Padróes de Identidade e Qualidade (PIQ), tratam da rotulagem (tanto gerais como específicos), materiais de embalagem, requisitos e procedimentos para registro e dispensa de registro, boas práticas de fabricação e procedimentos de higiene, aditivos, contaminantes tolerados e irradiação de alimentos (RJAILI, 1995 apud ALMEIDA-MURADIAN, 2011, p.3).

Para compreender melhor a complexidade do nosso sistema sanitário, trazemos abaixo um quadro com a distinção entre os diversos tipos de alimentos e os processos de produçáo que determinam o produto final.

O Ministério da Agricultura, Pecuária e Abastecimento - MAPA e a Agência Nacional de Vigilância Sanitária - ANVISA, são os órgãos centrais que controlam e fiscalizam os alimentos no Brasil.

Quadro1 - Classificação dos alimentos quanto à legislação sanitária: distinção simplificada dos órgãos responsáveis pela regulação de alimentos, de acordo com o tipo de alimento

\begin{tabular}{|c|c|c|}
\hline \multirow{5}{*}{$\begin{array}{l}\text { Alimentos regulamentados pelo } \\
\text { MAPA }\end{array}$} & \multirow{3}{*}{$\begin{array}{l}\text { Produtos exclusivamente } \\
\text { de origem animal }\end{array}$} & Carnes e derivados \\
\hline & & Leite e derivados \\
\hline & & Ovos e derivados \\
\hline & & Mel e derivados \\
\hline & & Pescados e derivados \\
\hline & \multirow[t]{3}{*}{ Bebidas em geral } & Não-alcoólicas \\
\hline & & Alcoólicas \\
\hline & & Fermentadas \\
\hline & Vegetais in natura & \\
\hline \multirow{4}{*}{$\begin{array}{l}\text { Alimentos regulamentados pela } \\
\text { ANVISA }\end{array}$} & \multirow[t]{2}{*}{ Demais alimentos processados } & Alimentos com registro obrigatório \\
\hline & & Alimentos com dispensa de registro \\
\hline & $\begin{array}{c}\text { Aditivos alimentares (registro } \\
\text { obrigatório) }\end{array}$ & \\
\hline & $\begin{array}{c}\text { Água mineral (registro } \\
\text { obrigatório) }\end{array}$ & \\
\hline
\end{tabular}

Fonte: NOLETO, 2016.

De maneira geral, o Ministério da Agricultura, Pecuária e Abastecimento - MAPA é responsável pelos produtos de origem animal: carnes, leite e derivados, ovos, pescados, produtos apícolas e margarina. Ainda sob sua alçada estáo os produtos de origem vegetal in natura, as bebidas alcoólicas e não alcoólicos e os vinagres. 
O Ministério da Saúde é responsável pelos alimentos industrializados em geral (com exceção dos produtos de origem animal e bebidas), aditivos, coadjuvantes de tecnologia, embalagens e materiais destinados a entrar em contato com os alimentos, alimentos para fins especiais e águas minerais e potáveis de mesa nos seus aspectos sanitários, pois o Ministério das Minas e Energias regulamenta a extração da água como um mineral.

O sistema sanitário brasileiro por sua vez é quem determina as regras para o processamento e consumo de alimentos seguros, ou seja, tem como finalidade estabelecer o que é seguro para ser consumido pela população. No entanto, é notório que a esterilização e homogeneização nos processos de produção e transformação alimentar é o que vem determinando o padrão de segurança do alimento. (NOLETO, 2016, p.1,2)

Com isso, a ampla diversidade alimentar dos povos que compóem seu patrimônio histórico e cultural fica ameaçada ou inviabilizada em detrimento do privilégio que se dá às grandes indústrias e corporaçóes industriais globalizadas, gerando uma completa inversão de valores sociais e culturais.

No Brasil, na área da saúde, a legislaçáo básica em vigor sobre os alimentos industrializados, que fundamenta a fiscalização da cadeia produtiva industrial e comercial para atender à especificação de segurança alimentar, é oriundo do Decreto-lei no 986, de 21 de outubro de 1969.

$\mathrm{Na}$ da agricultura, a legislação afim é a Lei no 1.283 , de 18 de dezembro de 1950, regulamentada pelo Decreto no 30.691, de 29 de março de 1952, que trata da inspeçáo industrial de produtos de origem animal. Além destas normatizaçôes, existem outras normas legais, não exclusivas ao alimento, mas que também tratam do tema em alguns dos seus artigos, como o Código Penal e o Código de Defesa do Consumidor, dentre outros. (ALMEIDA-MURADIAN, 2011, p. 3.)

A fiscalização desses alimentos tem como ponto fundamental o Sistema de Análise de Perigos em Pontos Críticos de Controle (APPCC), estabelecido pelo Ministério da Saúde em 1993, a partir da Portaria no 1.428 , que aprova o "Regulamento Técnico para Inspeção Sanitária de Alimentos" e estabelece "Diretrizes para estabelecimento de Padróes de Identidade e Qualidade (PIQ) para os serviços e produtos nas áreas de alimentos". Tal portaria teve sua fundamentação nas consideraçóes de que a prática da fiscalização sanitária de alimentos deve: integrar as açôes de vigilância sanitária e as avaliaçôes de risco epidemiológico dentro das prioridades locais, seguindo as determinaçóes do SUS; utilizar a inspeção como instrumento de fiscalização sanitária, abrangendo o conjunto das etapas que compóem a cadeia alimentar, incluindo suas inter-relaçôes com o meio ambiente, o homem e seu contexto socioeconômico (ALMEIDA-MURADIAN, 2011, p. 5).

O Regulamento Técnico sobre Condiçóes Higiênico-Sanitárias e Boas Práticas de Fabricação para Estabelecimentos de produtores e indústria de alimentos foi aprovado em 1997, pela Secretaria de Vigilância Sanitária do Ministério da Saúde, através da Portaria SVS/MS no 326/1997, regulamento este aplicado a toda pessoa física ou jurídica que possua, pelo menos, um estabelecimento no qual seja realizada alguma das seguintes atividades: produção/industrialização, fracionamento, armazenamento e transporte de alimentos industrializados (ALMEIDA-MURADIAN, 2011, p. 5).

Após estabelecer as Boas Práticas de Fabricação na Portaria 326/1997, para complementar sua efetivação a ANVISA publicou a Resolução da Diretoria Colegiada - RDC no 275/2002, que apresenta Procedimentos Operacionais Padronizados e a Lista de Verificação do cumprimento das Boas Práticas para os estabelecimentos industriais de alimentos (ALMEIDA-MURADIAN, 2011, p. 5). 
Além de todas essas, é necessário citarmos a Resolução RDC no 49, de 31 de outubro de 2013, que dispóe sobre a regulamentação para o exercício de atividade de interesse sanitário do microempreendedor individual, do empreendimento familiar rural e do empreendimento econômico solidário e dá outras providências (BRASIL, 2013).

Para além das normas e leis nacionais, existem os acordos internacionais com finalidade de oferecer alimentos seguros à população e legitimar práticas legais no comércio de alimentos, dentre eles destacando-se dois da Organização Mundial do Comércio (OMC): "Acordo sobre Obstáculos Técnicos ao Comércio (OTC)" e "Acordo sobre a Aplicação de Medidas Sanitárias e Fitossanitárias (SPS)" (ALMEIDA-MURADIAN, 2011, p. 9). Estes dois acordos determinam a saúde do consumidor como uma das prioridades; definem medidas regulamentares sanitárias e fitossanitárias para a garantia da inocuidade dos alimentos; e modificam as condiçóes de restrição de importação dos alimentos. Estes foram baseados em normas elaboradas por organismos internacionais como o Ofício Internacional de Epizootia - Saúde animal (OIE), Convenção Internacional de Proteção dos Vegetais (CIPV) e Comissão do Codex Alimentarius ${ }^{19}$. (Centro Franco-Brasileiro de Documentação Técnica e Científica, 2006, apud ALMEIDA-MURADIAN, 2011, p. 9.)

Assim, considerando a globalização dos processos produtivos, a legislaçáo brasileira de alimentos tem-se baseado não só em aspectos intrínsecos à realidade nacional, mas também incorpora fortemente o contexto internacional.

\section{LEGISLAÇÃO E VIGILÂNCIA SANITÁRIA}

No Brasil, vigilância sanitária, é definida como "um conjunto de açôes capaz de eliminar, diminuir, ou prevenir riscos à saúde e de intervir nos problemas sanitários decorrentes do meio ambiente, da produção e circulação de bens e da prestação de serviços de interesse da saúde", conforme art. $6^{\circ}$, paragrafo $1^{\circ}$ da Lei Orgânica da Saúde (Lei no 8.080, de 19 de setembro de 1990) que organizou o Sistema Único de Saúde.

A definição do Sistema Nacional de Vigilância Sanitária (SNVS) e a criação da Agência Nacional de Vigilância Sanitária (ANVISA), como autarquia vinculada ao Ministério da Saúde, deu-se pela Lei no 9.782/1999, sendo sua finalidade, prevista no seu art. 6º "promover a proteção da saúde da população, por intermédio do controle sanitário da produção e da comercialização de produtos e serviços submetidos à vigilância sanitária, inclusive dos ambientes, dos processos, dos insumos e das tecnologias a eles relacionados, bem como o controle de portos, aeroportos e de fronteiras". (BRASIL, 2018)

No entanto, seu marco inicial ocorreu no final da década de 1980 e início da década de 1990 , principalmente com a promulgação da Constituição Federal de 1988, onde se estabeleceu que, entre outros, a saúde é um direito de todos e um dever do Estado - conceito que inclui as açóes da vigilância sanitária. Nos dias atuais, a abrangência da vigilância sanitária é ampliada com o alargamento dos interesses difusos ${ }^{20}$, cujo conceito gira em torno da noção de qualidade de vida.

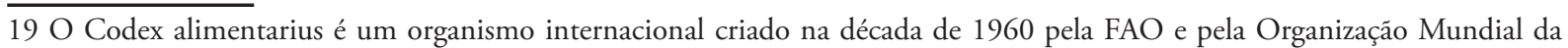
Saúde (OMS) para desenvolver normas, guias e recomendaçóes de boas práticas para a produçáo e comércio de alimentos, tendo como principal propósito a proteçáo da saúde e dos consumidores, visando também a promover a coordenação de todos os trabalhos para estabelecimento de padróes para alimentos desenvolvidos por organismos internacionais governamentais ou nấo (ALMEIDA-MURADIAN, 2011).

20 Os interesses difusos dizem respeito à sociedade de massa, na qual os grupos tomam lugar dos indivíduos. Refere-se a áreas e 
$\mathrm{Na}$ prática, as ações da vigilância sanitária limitam-se às atividades de fiscalização, observação dos fatos, concessão de licenças, julgamento de procedimentos irregulares e sançôes penais, função derivada de seu poder de polícia (EDUARDO; MIRANDA, 1998 apud AUGUST, 2016, p.113). Nota-se que, no Brasil, a relação produção- consumo desenvolvido na vigilância sanitária tem-se calçado no poder de polícia, ou seja, sua ação mais visivel é a de fiscalizadora, mesmo quando insuficientemente exercida.

A Vigilância Sanitária trabalha com o conceito de qualidade estrito senso, limitado ao aspecto sanitário e legal. Este conceito é insuficiente, pois não aborda outros elementos fundamentais, como o aspecto ecológico, o social, o cultural, além da aparência do produto, compondo um conceito de qualidade amplo (AUGUST, 2016, p.113).

O campesinato por sua vez, inserem-se em diversos contextos territoriais, que envolvem dimensões culturais, sociais e econômicas singulares, em que realizam suas atividades para subsistência familiar, cultivando alimentos de forma artesanal, visando os mercados locais. As autoridades de controle sanitário devem, portanto, no nosso sentir, identificar e interpretar a organização e a dinâmica das populações dos territórios e compreender como suas condiçôes econômicas, sociais e culturais funcionam, além das relaçóes dos atores sociais com seus espaços de vida e de trabalho.

\section{O CASO DO MERCADO POPULAR DE ALIMENTOS DE SÃO GABRIEL DA PALHA - ES}

O mercado popular de alimentos está situado em um município e região, diante de um contexto onde o modelo agrícola predominante é o agronegócio, baseado na monocultura do café, e na produção de alta escala, sempre com a utilização de adubos químicos, agrotóxicos, irrigação, mecanização pesada, e ainda com produção padronizada, prioritariamente para atender à exportação.

Nesse contexto, o campesinato deixa de ser camponês, e passam a ser agricultores familiares modernos, especializados com uso de tecnologia de ponta.

Este processo os distanciou da cultura de subsistência, dos seus costumes, dos saberes tradicionais, desconfigurando a identidade camponesa, por conta da substituição da autonomia a alimentar (valor de uso) pela busca do lucro (valor de troca) sob a hegemonia do modo de produçáo capitalista, que é totalmente dependente e voltado para o mercado.

Diante deste cenário, o Movimento dos Pequenos Agricultores (MPA), vem ao longo de sua história, debatendo com sua base, a necessidade de retomar a forma camponesa de produzir e de se relacionar com a natureza. Para tanto, é necessário sair da monocultura e voltar para o processo de diversificação da produção, só que agora alinhado sobre o conceito da agroecologia.

A agroecologia pode ser considerada uma construção recente; portanto, sua definição ainda não está consolidada. Constitui, em resumo, um conjunto de conhecimentos sistematizados, baseados em técnicas e saberes tradicionais (dos povos originários e camponeses) "que incorporam princípios ecológicos e valores culturais às práticas agrícolas que, com o tempo, foram desecologizadas e desculturalizadas pela capitalização e tecnificação da agricultura" (LEFF, 2002, p. 42).

temas de largo espectro social, tais como a ecologia, a qualidade de vida, a tutela de consumidores, a defesa dos direitos humanos, das etnias e outros. Esses temas ultrapassam os interesses dos indivíduos e alcançam toda a coletividade. (COSTA; ROZENFELD, 2000, p 17.) 
Com o avanço desse debate, surgiu a necessidade de criar espaços de comercializaçáo, como alternativa de geração de renda para as famílias camponesas, com objetivo de oferecer às famílias consumidoras produtos de qualidade, frescos, da região e com preços mais acessíveis, para além da feira livre que já existia na cidade.

A feira livre, mesmo considerada de grande importância nesse processo da comercialização direta, náo era suficiente, necessitava-se de um espaço que ficasse aberto todos os dias da semana, acessível às famílias produtoras que não tinham condiçóes de participar da feira. Além disso, o espaço permanente de comercialização representaria uma referência para as famílias camponesas e famílias consumidoras, criando uma relação mútua de solidariedade e ajuda entre quem produz e quem consome, entre o campo e cidade. Foram estas ideias que justificaram o início do processo de construção do espaço que veio a ser chamado de Mercado Popular de Alimentos.

\section{ANTECEDENTES HISTÓRICOS SOBRE E A CONSTRUÇÃO DO MERCADO POPULAR}

A agricultura na região, como já relatado brevemente acima, foi marcada pela monocultura do café conilon, sofrendo as consequências desse sistema monocultor de produção, tais como ataques de pragas e doenças, forte dependência e ingerência do mercado, perda de soberania alimentar, concentração de renda em um único período do ano, entre outros.

Em virtude disso, o Movimento dos Pequenos Agricultores vem trabalhando junto às comunidades camponesas, através de atividades de capacitação e formação das famílias, das mulheres, da juventude, dialogando e despertando para a importância da diversificaçáo da produção agropecuária de forma agroecológica. Nesse sentido, têm sido significativos os avanços que, no entanto, esbarravam na dificuldade da comercializaçáo.

Antes do MPA, as famílias estavam acostumadas a produzir e lidar com a venda do café, que é um produto de fácil comercialização, pois já havia toda uma rede de compra e venda, facilidade de armazenar e transportar, ao contrário dos produtos hortifrutigranjeiros, que precisariam chegar ao consumidor num prazo curto. Os agricultores não dispunham, em sua grande maioria, de meios de transporte para escoar sua produção até os mercados ou até as feiras; a produção era desarticulada. Por outro lado, as redes varejistas tinham toda uma logística montada em função da aquisição de produtos na CEASA ${ }^{21}$ e em sua grande maioria preferiam garantir a compra da produção da CEASA a adquiri-la dos camponeses da região. Faltava, assim, um processo de organização da produção e comercialização gerida pelas próprias organizaçóes dos agricultores. $\mathrm{O}$ resultado de todos esses empecilhos é que os camponeses não se motivavam a diversificar a produçáo, e a população local alimentava-se com produtos de procedência desconhecida e de baixa qualidade.

Com base nessa realidade, o Movimento dos Pequenos Agricultores, em 2007, começou a discutir um processo de organização da produção e comercialização que teve como eixo central o Mercado Popular de Alimentos, que atenderia diretamente as famílias camponesas dos municípios de São Gabriel da Palha, Vila Valério, Águia Branca, São Domingos do Norte, Pancas e Nova Venécia. A partir disso, foram realizadas muitas reunióes e debates com as famílias camponesas

21 CEASA são Centrais Estaduais de Abastecimento, empresas estatais ou de capital misto (público e privado), destinadas a aprimorar a comercialização e distribuição de produtos hortifrutigranjeiros, envolvendo três agentes principais: os comerciantes, os produtores e os compradores. Foram criadas na década de 1960 e implementadas na década de 1970, nos principais centros urbanos do País. Hoje, grande parte das frutas, legumes e flores comercializados em feiras, supermercados, restaurantes e sacolóes foram por eles comprados através das CEASAS (AGRIC. 2018). 
da região, com lideranças comunitárias e religiosas, com escolas, igrejas e com a população da cidade em geral, a fim de construir uma proposta que de fato atendesse às necessidades das famílias camponesas e das famílias consumidoras.

Com a adesão de todos os que participaram das conversas, e após muitas lutas e conquistas para viabilizar o espaço e a estrutura, no dia 09 de novembro de 2011, foi inauguração o Mercado Popular de Alimentos, sediado no município de São Gabriel da Palha, a fim de atender à região.

O Mercado Popular de Alimentos atende, assim, diversos objetivos: incentivar as famílias camponesas a diversificar a produção nas propriedades; garantir a comercialização da produção, superando o medo de produzir e não conseguir vender; gerar renda extra para as famílias camponesas; garantir renda para juventude, como incentivo para sua permanência no campo, por meio da comercialização de produtos alternativos e agroecológicos.

Este espaço preza por princípios e valores como o da produção de comida saudável para consumo da família e comercialização do excedente, bem como por garantir renda para a manutenção da família e da propriedade durante o ano, objetivando a "sobra" do café, ficando este como uma poupança para família a investir.

Dessa forma, o mercado popular carrega a mensagem política de Produzir, Organizar e Alimentar, ou seja, produzir alimento saudável, através da organização da produção das famílias camponesas e do incremento das relaçóes entre campo e cidade, no sentido de melhor alimentar o povo brasileiro, sendo um espaço acessível principalmente para a população trabalhadora.

\section{RELAÇÃO ENTRE CAMPO E CIDADE}

O Mercado Popular de Alimentos, na sua essência, tem como um de seus objetivos estreitar a relação entre campo e cidade. Não cabe à população urbana ser apenas consumidora, ela é parte de um processo, e o Mercado Popular de Alimentos deve ser capaz de estreitar essa relaçáo e suscitar esse debate. Para isso, precisa ser capaz de concretizar a mensagem política do MPA, ou seja, precisa estar sustentado em uma produção saudável.

Para dar conta dessa tarefa, não se pode partir do princípio de explorar os consumidores - ao contrário, a proposta é trazer comida boa, de qualidade, para a cidade, a preço justo tanto para quem produz, quanto para quem consome.

A noção de "preço justo" está diretamente ligada à autonomia da família produtora: é ela quem vai considerando os custos que teve para elaborar seu produto, estabelecer o valor pelo qual ele será comercializado, permitindo-lhe obter ganho, mas sem explorar. Em outras palavras, não é cobrado um preço exorbitante, apenas o necessário para cobrir os custos de produção da família produtora, custos este que engloba, a quantidade de trabalho necessário para produzir aquele alimento.

Relatos de consumidores evidenciam claramente que o espaço tem conseguido dar conta da tarefa que assumiu. Segundo eles passaram a comprar no Mercado porque é um espaço que vende produtos sem veneno e frescos.

Conseguem perceber facilmente a diferença entre os produtos que compram no Mercado Popular de Alimentos e os dos supermercados: "Aqui os produtos são mais gostosos, o sabor é outro, esse tem sabor de verdade, além de durar muito mais tempo." Consideram o preço dos produtos do Mercado Popular de Alimentos acessível: "Estive em Vitória e fiquei horrorizada com o preço do jiló e do quiabo, estava muito mais caro que aqui". 


\section{ESTRUTURAÇÃO ORGANIZATIVA DO MERCADOS POPULAR DE ALIMENTOS}

O Mercado Popular de Alimentos recebe a produção das famílias camponesas que são cadastradas, assim como seus produtos, todos identificados com o nome da família produtora, endereço, para que quem comprar possa saber de onde vêm e quem os produz.

Os produtos são organizados, ao chegar à sala de recepção da produção, são conferidos, pesados, contados, é feito o registro deles no sistema de computador (programa), são rotulados e colocados os preços. Após este processo, são expostos no Mercado de acordo com a correspondente: frutas e verduras nas bancas, as mais sensíveis são colocadas no expositor refrigerado de verduras e frutas; pães, doces, bolos e outros são expostos em estantes (gôndolas), e em mesas ornamentadas; leite, queijo, manteiga, água de coco e produtos refrigerados são expostos em balcão frigorífico lateral para laticínios; os congelados (carnes, salgados) são expostos nos freezers.

As famílias produtoras recebem o que foi vendido com desconto de $30 \%$ (trinta por cento). Havendo sobra da produçáo colocada no Mercado (ou seja, o que não foi vendido), a família poderá recolher, doar, dar o destino que desejar. Os 30\% (trinta por cento) recolhidos são destinados às despesas de manutençáo do Mercado (água, energia, sacolas, etiquetas, papelaria, pagamento de funcionários, manutenção das instalaçóes físicas, etc.). A família recebe, de 30 (trinta) em 30 (trinta) dias, informaçóes sobre o que foi vendido. Toda a produção que chega ao Mercado é registrada no cadastro da família, através do código que o produto recebe. Quando o produto passa pelo caixa, o sistema dá baixa, de forma que, no fechamento do mês, sabe-se quanto e o que foi vendido, ficando para a correspondente família $70 \%$ (setenta por cento) do que houver sido comercializado.

Existe uma equipe que trabalha no Mercado realizando atividades que vão desde receber produção até cadastrar, organizar, vender, administrar e limpar o espaço. É uma espécie de feira permanente. $\mathrm{O}$ funcionamento do Mercado acontece de segunda a sexta-feira, das 8 às 17 horas, e, aos sábados, das 8 horas às 12 horas, seguindo os acordos do comércio local e feriados.

\section{DESAFIOS}

Ao longo dos oito anos de existência do Mercado Popular de Alimentos, muitos desafios surgiram. Alguns foram superados, outros amenizados. Por ser um espaço de enfrentamento, os desafios são variados e constantes, alguns de ordem mais interna - afinal de contas gerir um mercado não é fácil, sobretudo com esse viés político. No entanto, destacamos a barreira de mercado como o principal desafio que vem sendo posto e que tampouco consegue ser resolvido de forma rápida.

Como já exposto anteriormente, a lógica de mercado em São Gabriel da Palha não destoa da realidade nacional dos controles, monopólios dos alimentos. No Estado do Espírito Santo, há uma gama de redes responsáveis pelo abastecimento urbano dos alimentos, destacando-se quatro grandes redes de supermercados, de distribuição, sendo estas a Central de Compras, a Rede Show, a Rede Multimarket e a Rede Smar, que congregam diversas unidades, com lojas distribuídas em todo o estado (LUCCI, 2013). A maior parte da produção comercializada nestas redes advém dos CEASAs: muito pouco ou raras vezes se compram produtos dos agricultores locais. No município de São Gabriel da Palha, por seu turno, existem quatro grandes supermercados, sendo que um deles é da rede Central de Compras, o Cricaré.

Sem qualquer diferença dos grandes estabelecimentos comerciais citados, o funcionamento regular do Mercado Popular de Alimentos depende do atendimento a diversas normas, regras e 
procedimentos administrativos correlatos: a emissão de um alvará de funcionamento, emitido pela Prefeitura local; de alvará do Corpo de Bombeiros; de alvará sanitário; e a adequação dos produtos comercializados no Mercado Popular de Alimentos à legislação sanitária vigente. A regularização destes produtos compete, em parte, à Vigilância Sanitária Municipal e Estadual e, em parte ao Ministério da Agricultura, Pecuária e Abastecimento (MAPA).

A regularização dos produtos frente a este controle, no entanto, mostra-se um grande empecilho para os camponeses, dado que a produção artesanal tem suas especificidades e particularidades, que são desconsideradas pela legislaçáo - toda produzida a partir do prisma da grande produção industrial. Com isso muitos dos produtos vendidos não estão devidamente registrados perante os órgãos competentes.

No atual cenário político e econômico que o país vem vivendo, somado à perca da produção provocada pela seca dos últimos anos no estado do Espírito Santo, ao corte das políticas públicas (Programa Aquisição de Alimentos (PAA), Política Nacional de Alimentação Escolar (PNAE), Moradia Camponesa, Bolsa Família), a Reforma trabalhista, a falta de investimentos e políticas voltadas para agricultura camponesa, acentua e agrava a crise econômica da população, gerando dentre outros problemas, o aumento do inadimplemento no campo, desemprego, aumento do trabalho informal e escravo, e alta nos preços dos alimentos.

Não diferente do comércio tradicional local, o mercado popular também enfrenta dificuldades nas vendas da produção, que vem caindo de forma considerável, agregando ainda, o aumento nas despesas com produtos e serviços como a gasolina, energia, material de expedientes entre outros, que vem colocando a manutençáo deste espaço, como desafio principal para o Movimento dos Pequenos Agricultores da região de São Gabriel da Palha.

\section{CONSIDERAÇÕES FINAIS}

Ao longo dos estudos desenvolvidos este trabalho, foi possível perceber, analisar e entender melhor, a forma organizativa e os desafios referente a situação da comercialização e da produção realizadas pelas famílias camponesas de São Gabriel da Pala, no que se refere a legislaçáo brasileira vigente.

É notória a contradição vivida na atual sociedade, sobretudo no que concerne à questão dos alimentos, enquanto se tem uma grande população brasileira e mundial passando fome, vivendo em situação de insegurança alimentar, inúmeros e crescentes dados de doenças causados por alimentos contaminados e danosos à saúde, há uma barreira imposta pelo mercado, que impede as famílias camponesas de produzir e comercializar alimentos dentro da lógica camponesa. Mesmo sendo estas, responsáveis por $70 \%$ (setenta por cento) dos alimentos que estáo na mesa do povo brasileiros (IBGE, 2010) de forma saudáveis e em respeito e harmonia ao meio ambiente.

$\mathrm{Na}$ atual configuração da sociedade, onde o Estado tem o monopólio das leis, é fato que a legislação atual tem servido de escudo para as grandes corporaçóes que atua em escala global no ramo dos alimentos, pautado no monopólio e na artificialidade dos mesmos, onde o objetivo visa o lucro em detrimento da vida.

As repercussôes e contradiçôes do atual modelo, por sua vez, podem ser percebidas quando observamos a atuação do Estado sobre a produção camponesa, na tentativa de padronizar as normas e as exigências, criando uma única legislação para atender a todos.

Neste sentido, o Estado atua de forma excludente, desigual, injusta e ilegítima - e até mesmo cruel - para com as famílias camponesas, que jamais conseguiriam atender às mesmas exigências impostas para as grandes corporaçóes. 
A Legislação vigente como um todo, no caso deste trabalho mais especificamente a legislaçáo relativa à Vigilância Sanitária, deve ter como verdadeiro fundamento garantir a toda a população um alimento de qualidade, saudável, assegurar a saúde de todos e todas, e não simplesmente atender ao poder hegemônico do capital, voltado o lucro.

É pelo direito de comercializar a produção camponesa que se defende uma legislaçáo mais justa e legítima, que só será possível quando o Estado considerar a pluralidade, a diversidade dos povos com suas cultura e saberes e diferenças regionais. Isto não significa defender uma produção desregulamentada, mas, ao contrário, que seja realmente garantida a qualidade dos alimentos, levando em conta as diversas e diferentes formas tradicionais de produzir e comercializar.

O Mercado Popular de Alimentos é um sonho em realização, sonho este, feitos a muitas mãos, por pessoas que compreendem que "sonho que se sonha só é só um sonho, sonho que se sonha juntos é realidade!!!"

\section{REFERÊNCIAS}

AGRIC. O que é CEASA? Disponível em: www.agric.com.br. Acessado em 27 fev. 2018.

ALMEIDA-MURADIAN, Ligia Bicudo de. Vigilância Sanitária: tópicos sobre legislação e análise de alimentos. Rio de Janeiro: Guanabara Koogan, 2011.

BANCO MUNDIAL. Rising global interest in farmland: Can it yield sustainable and equitable benefits? Washington D.C., 07 de setembro de 2010. Brasil. Disponível em:https://issuu.com/world.bank.publications/docs/9780821385913. Acesso:25 abr.2018.

BRASIL. Constituição (1988). Vade mecum Saraiva. 21.ed. atual e ampl. São Paulo: Saraiva. 2016.

BRASIL. Lei no 8.080, de 19 de setembro de 1990. Disponível em: http://conselho.saude.gov.br/legislacao/ lei8080_190990.htm. Acessado em 27 nov.2019.

BRASIL. Lei. no 9.782 de 26 de janeiro de 1999. Disponível em: http://www.planalto.gov.br/ccivil_03/Leis/ L9782.htm. Acessado em 27 nov. 2019.

CAMPELO, Lilian. Terras na região do Cerrado viram alvo de especuladores. Brasil de fato: uma visão popular do Brasil e do Mundo. Disponível em: https://www.brasildefato.com.br/2017/02/06/terras-na-regiao-do-matopiba-viram-alvo-de- especuladores/. Acesso: 13 abr. 2018.

DELGADO, Guilherme Costa. Economia do agronegócio (2000) como pacto de poder com os donos da terra. Revista da Associação Brasileira de Reforma Agrária, p. 60-68, jul. 2013. Edição especial.Disponível em:http://www.reformaagrariaemdados.org.br.pdf. Acesso: 12 abr. 2018.

CALDART, Roseli Salete; PEREIRA, Isabel Brasil; ALENTEJANO, Paulo; FRIGOTTO, Gaudêncio. (Org.). Dicionário da Educação do Campo. Rio de Janeiro, São Paulo: Escola Politécnica de Saúde Joaquim Venâncio, Expressão Popular, 2012.

ESTEVE, Esther Vivas. O negócio da Comida: quem controla nossa Alimentação? 1.ed. São Paulo. Expressão Popular, 2017. 
FISCHER, Augusto. Percepção das normas da vigilância Sanitária pelos Agricultores Familiares de Joaçaba, Herval D’Oeste e Luzerna. Artigo. 2016. Disponível em: http://www.scielo.br/scielo.php?script=sci_arttext\&pid=S0103-20032012000300007. Acesso:23 nov.2017.

KÜNZLI, Willi Sebastian. Investimento estrangeiro em Terras no Brasil à Luz do Direito Internacional. 2015. Dissertação (Mestrado em Direito Internacional) - Faculdade de Direito,USP, São Paulo. Disponível em: http://www.teses.usp.br/teses/disponiveis/2/2135/tde- 17122015-081241/pt-br.php. Acesso: 19 marc.2018.

Leff, E. Agroecologia e saber ambiental. Agroecologia e Desenvolvimento Rural Sustentável, Porto Alegre, v. 3, n. 1, p. 36-51, jan.-mar. 2002.

LUCCI. P. H. G. Geografia dos Alimentos no Espírito Santo. 2013. 245 f. Dissertação (Mestrado em Geografia) - Centro de Ciências Humanas e Naturais, Universidade Federal do Espírito Santo. Vitória. 2013.

MATIELO, Cristina. Impasses da comercialização de alimentos da agricultura camponesa em função da legislação vigente: um estudo do mercado popular de alimentos em são gabriel da palha - ES. 2018. 103 f. (Monografia em Direito) - Universidade Estadual de Feira de Santana - Bahia 2018.

NOLETO, Rodrigo Almeida. A produção brasileira de alimentos e as dificuldades enfrentadas para sua regularização sanitária. Artigo. Cerratinga. 2016. Disponível em: http://www.ispn.org.br/a-producao-brasileira-de-alimentos-e-as-dificuldades-enfrentadas- para-sua-regularizacao-sanitaria/. Acessado em $27 \mathrm{fev}$. 2018.

PLOEG, Jan Douwe Van Der. Camponeses e impérios alimentares: lutas por autonomia e sustentabilidade na era da globalizaçáo. Porto Alegre. Editora da UFRGS, 2008.

ROZENFELD, Suely (org.). Fundamentos da Vigilância Sanitária. Rio de Janeiro: Editora FIOCRUZ, 2000.

SANTOS, Claudinei Lucio Soares. O processo de estrangeirização de terras no brasil, como forma de reprodução do capital na agricultura: uma análise sobre os aspectos jurídicos e legislativos. 2018. 86 f. (Monografia em Direito) - Universidade Estadual de Feira de Santana - Bahia 2018.

SAUER, Sérgio; LEITE, Sergio Pereira. Expansão agrícola, preços e apropriação de terra por estrangeiros no Brasil. Rev. Econ. Sociol. Rural [online]. 2012, vol.50, n.3, p.503-524. Disponível em: http://www.scielo. br/scielo.php?script=sci_arttext\&pid=S0103-20032012000300007. Acesso:23 nov.2017.

ZIEGLER, Jean. Destruição em massa: geopolítica da fome. São Paulo: Cortez, 2013. 